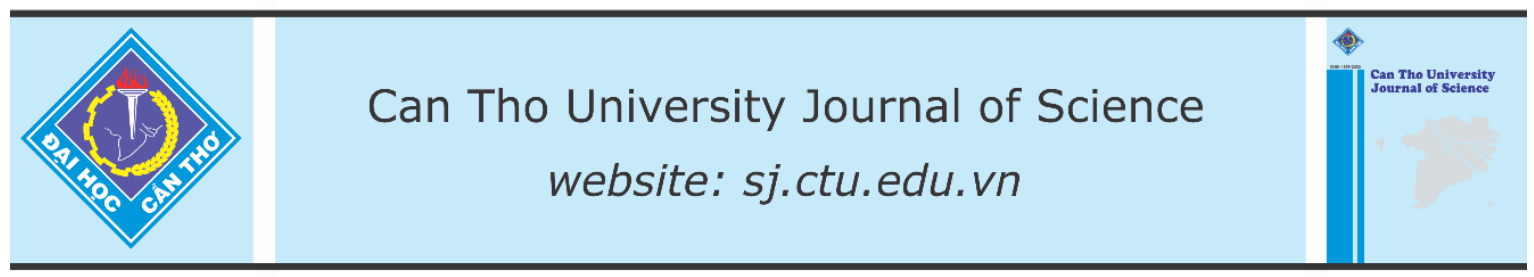

DOI: 10.22144/ctu.jen.2020.006

\title{
The preparation of a fine tip calcium ion selective electrode
}

Nguyen Van Dat ${ }^{1}$, Huynh Thanh Tuan ${ }^{1}$, Ho Quoc Phong ${ }^{2}$, Huynh Lien Huong ${ }^{2}$,

Nguyen Thanh Dat ${ }^{3}$, Ong Thi My Hien ${ }^{4}$, Ronny Purwadi ${ }^{5}$

${ }^{1}$ College of Natural Sciences, Can Tho University, Vietnam

${ }^{2}$ College of Engineering Technology, Can Tho University, Vietnam

${ }^{3}$ Bachelor of Chemistry, Course 43, College of Natural Sciences, Can Tho University, Vietnam

${ }^{4}$ The Korea Institute of Science and Technology (KIST), Republic of Korea

${ }^{5}$ Department of Chemical Engineering, Institut Teknologi Bandung, Indonesia

*Correspondence: Nguyen Van Dat (email: nvdat@ctu.edu.vn)

\section{Article info.}

Received 25 Aug 2018

Revised 22 Dec 2018

Accepted 31 Mar 2020

\section{Keywords}

Cocktail A, detection limit,

EGTA, ISE, silanization

\section{ABSTRACT}

The purpose of this present study is to make a fine tip $\mathrm{Ca}^{2+}$-selective electrode. Detection limit is found at $\mathrm{pCa}$ around 7.5 in $\mathrm{Ca}^{2+}$ buffer solution. The changes in electromotive force induced between two solutions for 10fold change in $\mathrm{Ca}^{2+}$ concentration are close to $30 \mathrm{mV}$. This electrode characteristics were found for single-barrelled microelectrodes of 72.6 $n m$ diameter tip and an internal filling solution buffered for $p C a$ of 6 .

Cited as: Dat, N.V., Tuan, H.T., Dat, N.T., Phong, H.Q., Huong, H.L., Hien, O.T.M. and Purwadi, R., 2020. The preparation of a fine tip calcium ion selective electrode. Can Tho University Journal of Science. 12(1): 45-49.

\section{INTRODUCTION}

Ion-selective electrodes (ISEs) are electrochemical ion sensors that convert the activity of a target ion into an electrical potential as the measurable signal (Hu et al., 2016). There are several advantages such as high selectivity, quick analysis, low cost, wide variety of tested ions, and small sample size in this technology (Vijayalakshmi and Selvi,2013).

In the study of Eriksen et al. (2001), the copper in natural water was determined by the use of ISE. Similarly, the determination of lead in drinking water by means of ISE has also been reported by $\mathrm{Ce}$ resa et al. (2001). In another study, Miller et al. (2001) developed an ISE with internal solution for the direct measurement of $\mathrm{Na}^{+}$in plant cells. The calcium electrode offers great possibilities for the determination of the total calcium content in blood (Melchior-Rasmussen, 1972). Recently, the determination of calcium ions in sap using carbon nanotube-based ion-selective has been described (Hernandez et al., 2010). In more recent years, a new simple, highly specific and calcium selective electrode has been prepared by Vijayalakshmi and Selvi (2013). This calcium selective electrode was also successfully used in the analysis of concentration of calcium ion in various real samples (Vijayalakshmi and Selvi, 2013).

However, there has been very little research reported on a fine tip ISE. The present work is aimed to manufacture a fine tip $\mathrm{Ca}^{2+}$-selective electrode. This electrode can combine with the scanning ion conductance microscope (SICM-a asembly for scanning living cells without damaging them or a 
specific scanning protocol that prevents the tip of the micropipette from making direct physical contact with the specimen) (Korchev et al., 1997). For these purposes, a micropipette with a fine tip was prepared in the first step, followed by evaluating characteristics of the $\mathrm{Ca}^{2+}$-selective electrode with phosphate buffered saline as an internal filling solution.

\section{MATERIALS AND METHODS}

\subsection{Materials}

$N$-(Trimethylsilyl)dimethylamine, ethylene glycolbis(2-aminoethylether) $-N, N, N^{\prime}, N^{\prime}$-tetraacetic acid (EGTA) were from Sigma. Calcium chloride dehydrate and cocktail A $(0.1 \mathrm{~mL})$ were obtained from Fluka. However, it was impossible to obtain information on the chemical composition of cocktail A for commercial confidentiality reasons. Phosphate buffered saline was purchased from Biowhittaker (Table 1).

Table 1: The composition of phosphate buffered saline (PBS)

\begin{tabular}{lrrr}
\hline & \multicolumn{3}{c}{ Formula } \\
\cline { 2 - 4 } & $\mathbf{K H}_{2} \mathbf{P O}_{4}$ & $\mathbf{N a C l}$ & $\mathbf{N a}_{2} \mathrm{HPO}_{4}$ \\
\hline Content, $\mathrm{mg} / \mathrm{L}$ & 144 & 9,000 & 795 \\
\hline
\end{tabular}

2.2 Methods

\subsubsection{Manufacturing a fine tip microelectrode}

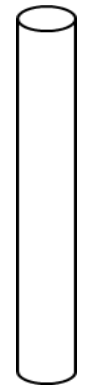

(a)

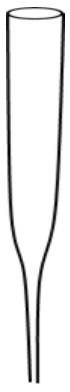

(b)
Fig. 1: (a) Scheme of a capillary and (b) a fine tip microelectrode

Fig. 1 displays a capillary was pulled from borosilicate glass with filament $(O . D=1 \mathrm{~mm} ; \mathrm{I} . \mathrm{D}=0.5 \mathrm{~mm}$; length $=10 \mathrm{~cm}$ ) with a $P-2000$ micropipette puller NANOLAB, KAIST, Korea. Then, the capillaries were placed in a petri dish and backed at least three hours at $150^{\circ} \mathrm{C}$ to remove traces of water.

\subsubsection{Silanization}

The structure of silicate glasses (Fig. 2) is dominated by the $\mathrm{SiO}_{4}$ unit of pure silica (Greaves et al., 1981).

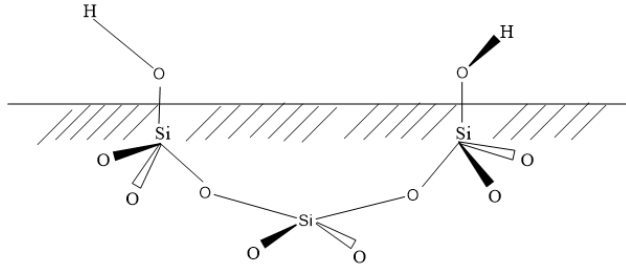

Fig. 2: The structure of the surface of glass

The surface of glass is hydrophilic and a column of liquid sensor (which is hydrophobic) was introduced into the tip of an untreated glass micropipette it would be displaced by any aqueous solution in which the tip was immersed (Munoz et al., 1983).

The process of silanization consists in replacing the hydrogen of the surface hydroxyl group by a covalently bound silicon atom that carries hydrophobic groups (Holland, 1964). As a result, the hydrophilic hydroxyl groups are replaced by hydrophobic groups. Hydroxyl groups on the surface of glass can be made to react with the class of silicon compounds known as silanes (Munoz et al., 1983). In this experiment, the reaction between the surface of glass, $\mathrm{R}-$ $\mathrm{OH}$, and silanes $\quad\left(\mathrm{CH}_{3}\right)_{3} \mathrm{Si}-\mathrm{N}\left(\mathrm{CH}_{3}\right)_{2}$, can be presented by the following equation (Miller JM., 2005):

\section{$\mathrm{R}-\mathrm{OH}+\left(\mathrm{CH}_{3}\right)_{3} \mathrm{Si}-\mathrm{N}\left(\mathrm{CH}_{3}\right)_{2} \longrightarrow \mathrm{R}-\mathrm{OSi}\left(\mathrm{CH}_{3}\right)_{3+}$ $\left(\mathrm{CH}_{3}\right)_{2} \mathrm{NH}$}

$\mathrm{N}$ - (trimethylsilyl) -dimethylamine was injected into the tip of capillary. The reagent was allowed to react in the vapor phase for 12 hours at $200^{\circ} \mathrm{C}(\mathrm{Am}-$ mann et al., 1987).

\subsubsection{Filling membrane (coctail A)}

By means of a micromanipulator (Scanning Electro Microscope Olympus SZ51 at Biosensor Lab, KRISS, Korea), a short column of the $\mathrm{Ca}^{2+}$-selective sensor was introduced into the tip by capillarity, or suction if necessary.

\subsubsection{Preparing for internal solution}

In the region of $\mathrm{pCa}=2-4\left(\mathrm{pCa}=-\lg \left[\mathrm{Ca}^{2+}\right]\right)$, it was found that the solution prepared very carefully by normal dilution techniques was satisfactory (Ammann et al., 1987). At low concentration, $\mathrm{Ca}^{2+}$ will be lost by adsorption on glass or reaction with impurities. An alternative is to prepare a metal ion buffer from the metal $\left(\mathrm{Ca}^{2+}\right)$ and a suitable ligand (EGTA) (Tsien and Rink, 1981). The preparation for the buffer solution has been listed in Table 2 with reference of Ammann et al. (1987). 
Table 2: The composition of buffer solution

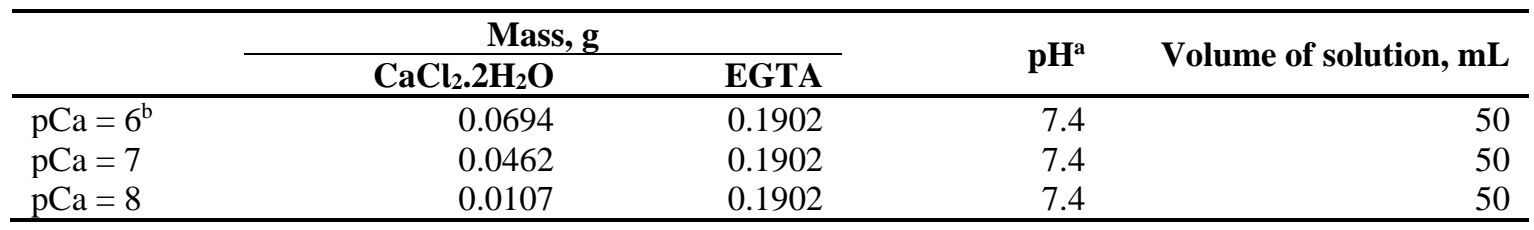

${ }^{a}$ Controlling $p H$ value at 7.4 using $\mathrm{KOH}$ solution; ${ }^{b} \mathrm{pCa}=-\lg \left[\mathrm{Ca}^{2+}\right]$

\subsubsection{Making reference electrode}

The most commonly used reference electrode in biological measurements is the $\mathrm{AgCl}$ coated $\mathrm{Ag}$ wirethe $\mathrm{Ag} / \mathrm{AgCl}$ electrode. These electrodes are easy to manufacture, and the electrode potential has a relatively small temperature coefficient. If the $\mathrm{Ag} / \mathrm{AgCl}$ electrode is placed in saturated $\mathrm{KCl}$, it is written as $\mathrm{Ag} / \mathrm{AgCl}$ (solid)/KCl(saturated, aqueous) (Fry and Langley, 2002). Reaction at the interface for an $\mathrm{Ag} / \mathrm{AgCl}$ electrode is:

$$
\mathrm{AgCl}(\mathrm{s})+\overline{\mathrm{e}} \longrightarrow \mathrm{Ag}(\mathrm{s})+\mathrm{Cl}^{-}(\mathrm{aq})
$$

The following procedure is for the preparation of a reference electrode-the $\mathrm{Ag} / \mathrm{AgCl}$ electrode: Firstly, a chlorinated silver wire was prepared by soaking silver wire in a solution of $\mathrm{HNO}_{3}$ about one hour followed by cleaning with distilled water. It was then soaked in a $\mathrm{HCl}$ solution about 10 minutes and cleaned by water again. Secondly, reference electrode was prepared from micropipette filled with 3 $\mathrm{M} \mathrm{KCl}$ solution. Finally, reference electrode was completed by insertion of a chlorinated silver wire which was fixed at the end of the original capillary tubing by a drop of wax.

\subsubsection{Making a measurement}

In order to measure electromotive force (EMF), the following electrochemical cell is constituted:

$\mathrm{Ag}|\mathrm{AgCl} \quad| \mathrm{KCl} \|$ bridge electrolyte $\mid$ sample $\|$ membrane $\|$ inner filling solution $|\mathrm{AgCl}| \mathrm{Ag}$

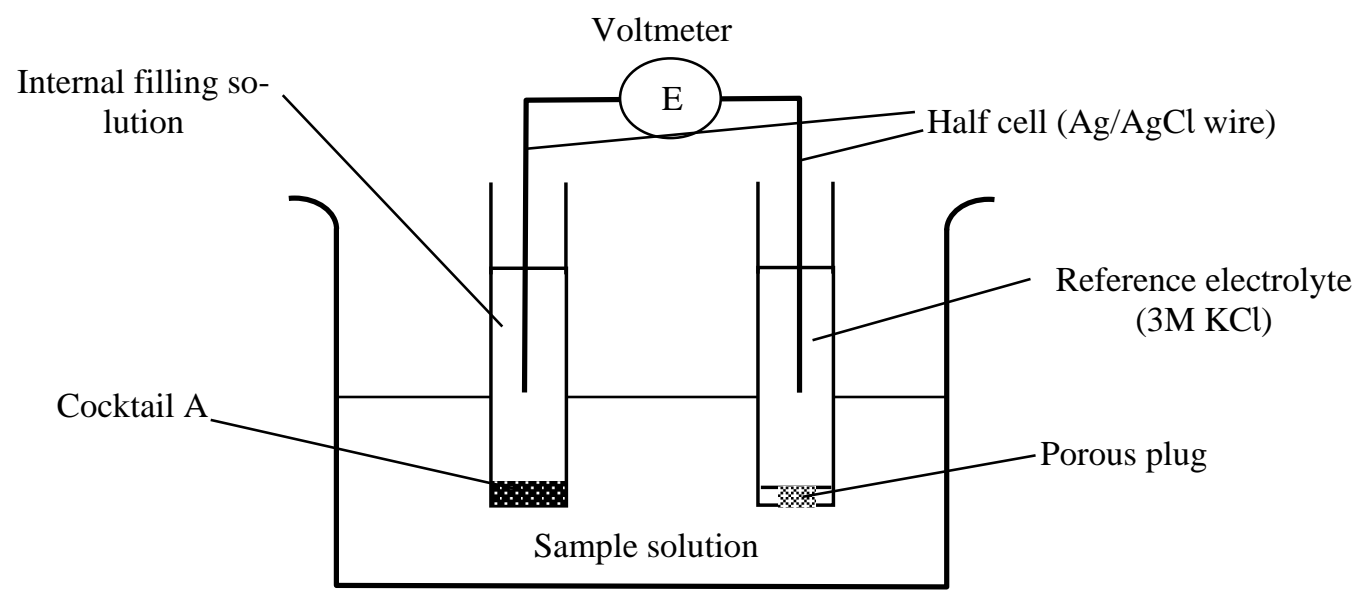

Fig. 3: Schematic diagram of EMF measurement

All potential measurements were made by means of a digital $\mathrm{pH}$ meter benchtop-Orion 3 Star at Biosensor Lab, KRISS, Korea.

\section{RESULT AND DISCUSSION}

\subsection{Manufacturing a fine tip $\mathrm{Ca}^{2+}$-selective electrode}

A fine tip microelectrode with $72.6 \mathrm{~nm}$ diameter tip and very smooth tip surface (Fig. 4) was manufactured in this research. The finding infers that this microelectrode demonstrated the potential as an excellent candidate for scanning ion conductance microscope (SICM) system.
The pipette was mounted on a micromanipulator and immersed into the membrane solution (cocktail A). Cocktail A will easily penetrate into the tip of pipette owing to capillary force (liquid membranes are organic cocktails and hydrophobic). The time to obtain cocktail column length required depends on tip diameter and efficiencies of silanization.

Besides, silanization of charged surfaces produces a monomolecular hyrophobic finish allowing the organic liquid membrane to bed comfortably in the tip of the electrode, no longer being displaced by the electrolyte (Munoz et al., 1983). 


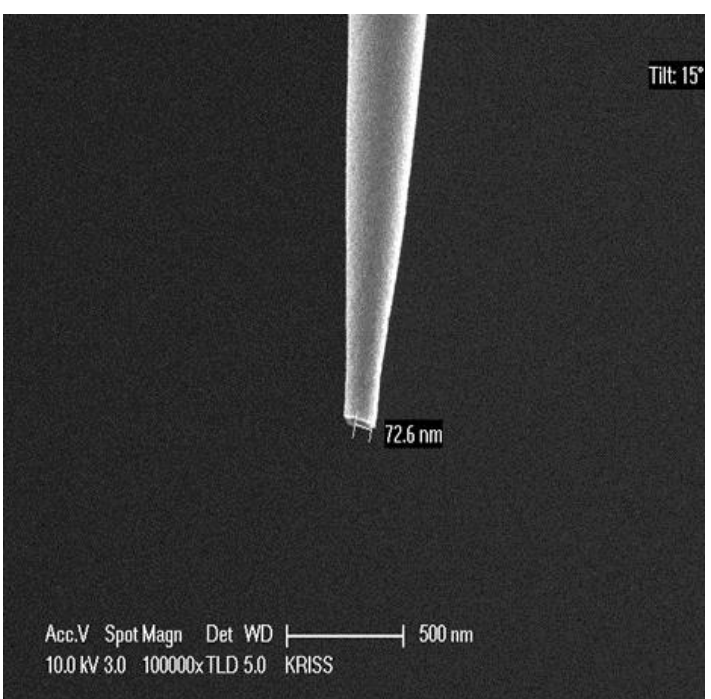

Fig. 4: Scanning electron micrographs of a micropipette tip

(conditioned in: $H E A T=420, F I L=4, V E L=30, D E L$ = 140, PULL $=250$ )

Membrane column length should be short. If the liquid membrane column within a microelectrode is so long that part of it remains above the surface level of a warmed experimental bath, change in bath temperature or surface level can give rise to changes in electrode output, thereby causing serious noise and errors in quantitative ion measurement.

\subsection{Electromotive force measurements}

EMF is defined as the difference between the potentials of two electrodes immersed into a solution. A pair of electrodes immersed into a solution makes a galvanic cell. One of the electrodes is called indicator electrode in the galvanic cell and obeys the Nernst equation. The other electrode is the reference one, and its potential is constant.

A calibration curve is a plot of the potential differences of an ion-selective electrode/reference electrode pair against the logarithm of the ionic activity or concentration of a particular species (called an ion-selective electrode assembly). The potential differences should be plotted on the ordinate (vertical axis) with the more positive potentials at the top of the axis and the logarithm of the ion activity (or concentration) plotted on the abscissa with increasing activity (or concentration) to the right (i.e. decreasing pIon values to the right) (Fry and Langley, 2002).

Calibration curve representing EMF versus the logarithm of the ion concentration revealed a typical ion-selective electrode response shown in Fig. 5. The linear working range was determined to be -7 $<\lg \left[\mathrm{Ca}^{2+}\right]<-3$ (i.e. $3<\mathrm{pCa}=-\lg \left[\mathrm{Ca}^{2+}\right]<7$ ).

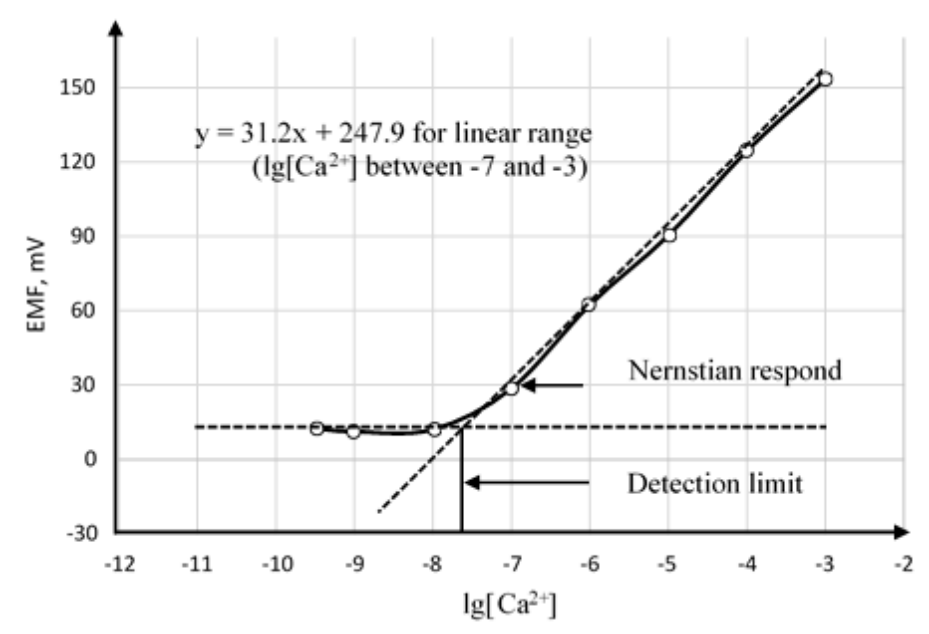

Fig. 5: A calibration curve showing detection limit and the region of Nernstian response of $\mathrm{Ca}^{2+}$-selective electrode

Detection limit is estimated from the calibration curve as the concentration defined by the intersection of the extrapolated two linear regions of the curve. Fig. 5 shows that the detection limit was estimated to be $\lg \left[\mathrm{Ca}^{2+}\right] \approx-7.5$ (i.e. $\left[\mathrm{Ca}^{2+}\right]=10^{-7.5} \mathrm{M}$ ).
An ion-selective electrode assembly has a Nernstian response over a given range of ion concentration, $C_{i}$ (or activity, $\mathrm{a}_{\mathrm{i}}$ ) if the calibration curve is linear with a slope of $2.303103 \times \mathrm{RT} / \mathrm{z}_{\mathrm{i}} \mathrm{F} \mathrm{mV}$ per 10 -fold change 
of $\mathrm{C}_{\mathrm{i}}$ (per unit change of $\mathrm{pC}_{\mathrm{i}}$ ). At $25^{\circ} \mathrm{C}$, this is $59.16 / \mathrm{z}_{\mathrm{i}} \mathrm{mV}$ per unit change of $\mathrm{pC}_{\mathrm{i}}$.

The slope of the curve in the linear range (i.e. the sensitivity of the $\mathrm{Ca}^{2+}$-selective electrode) was determined to be $31.2 \mathrm{mV} /$ decade, which is in complete accordance with the Nernst equation for positively-charged divalent ions.

The time between when the ion-selective electrode assembly is brought into contact with a new solution and when the measured potential differences is within $1 \mathrm{mV}$ of the final steady-state value. The response time is an important factor for ion selective electrodes. Response time was recorded over a $\mathrm{Ca}^{2+}$ concentration range of $10^{-7}-10^{-3} \mathrm{M}$. The electrode reached equilibrium within a very short period of 10 seconds, so $\mathrm{Ca}^{2+}$-selective electrode can be used for SICM system.

\section{CONCLUSIONS}

The electrode exhibited good properties with regard to the tip diameter $(72.6 \mathrm{~nm})$, the slope $(\approx 30 \mathrm{mV} /$ decade), lower detection limit $(\approx 7.5)$, and response time $(<10 \mathrm{~s})$. It is concluded that the $\mathrm{Ca}^{2+}$ selective electrode demonstrated the potential as a promising candidate for as a useful analytical tool for many practical applications. Especially, it possible to combine with SICM for imaging a living cell, however, this application requires further studies.

\section{ACKNOWLEDGMENT}

An honorable mention goes to Prof. Choong K. Rhee, Dr. Dal Hyun Kim and Ms. Sunmi for their supports in completing this work. Without their support and enthusiasm, this study would not have been possible. This study was supported by Korean instututions and universities including: The Korea Research Institute of Standards and Science (KRISS); Korea Advanced Institute of Science and Technology (KAIST), Department of Chemistry-Chungnam National University (CNU), and Department of Chemistry-Pusan National University (PNU).

\section{REFERENCES}

Ammann, D., Bührer, T., Schefer, U., Müller, M., and Simon, W., 1987. Intracellular neutral carrier-based Ca2+ microelectrode with subnanomolar detection limit. European Journal of Physiology. 409(3): 223-228.
Ceresa, A., Bakker, E., Hattendorf, B., Gunther, D., and Pretsch, E., 2001. Potentiometrie Polymeric Membrane Electrodes for Measurements of Environmental Samples at Trace Levels: New Requirements for Selectivities and Measuring Protocols, and Comparison with ICPMS. Anal. Chem. 73: 343-351.

Eriksen, R.S., Mackey, D.J., van Dam, R., and Nowak, B., 2001. Copper speciation and toxicity in Macquarie Harbour, Tasmania: an investigation using a copper ion selective electrode. Mar Chem. 74(2-3): 99-113.

Fry, C.H., and Langley, S.E.M, 2002. Ion-Selective Electrodes for Biological Systems. CRC Press.

Greaves, G.N., Fontaine, A., Lagarde, P., Raoux, D. and Gurman, S.J., 1981. Local structure of silicate Glasses. Nature (Loud.). 293: 611-616.

Holland, L., 1964. The Properties of Glass Surfaces. Chapman and Hall, London.

Hu, J., Stein, A., and Buhlmann, P., 2016. Rational design of all-solid-state ion-selective electrodes and reference electrodes. Trends in Analytical Chemistry. 76: 102-114.

Miller JM., 2005. Chromatography: Concepts and Contrasts. John Wiley and Sons.

Korchev, Y.E., Bashford, C.L., Milovanovic, M., Vodyanoy, I., and Lab, M.J., 1997. Scanning Ion Conductance Microscopy of Living Cells. Biophysical Journal. 73(2): 653-658.

Rasmussen, MJ., 1972. Lecture for the Danish Society for Clinical Chemistry, Copenhagen.

Miller, A.J., Cookson, S.J., Smith, S.J. and Wells, D.M., 2001. The use of microelectrodes to investigate compartmentation and the transport of metabolized inorganic ions in plants. J. Exp. Bot. 52: 541-549.

Munoz, J.L., Deyhimi, F., and Coles, J.A., 1983. Silanization of glass in the making of ion-sensitive microelectrodes. Journal of Neuroscience Methods. 8: 231-247.

Hernandez R., Riu J., and Rius, FX.., 2010. Determination of calcium ion in sap using carbon nanotube-based ion-selective electrodes. Analyst. 135: 1979-1985.

Tsien, R.Y. and Rink, T.J., 1981. Ca2+-selective electrode: a novel PVC-gelled neutral carrier mixture compared with other currently available sensors. J Neurosci Methods. 4: 73-86.

Vijayalakshmi, A., and Selvi, J.T., 2013. A new simple method for the preparation of calcium ion selective electrode and its analytical applications. Chemical Science Transaction. 2(S1): S246-S250. 